\title{
Boat Noise and Black Drum Vocalizations in Mar Chiquita Coastal Lagoon (Argentina)
}

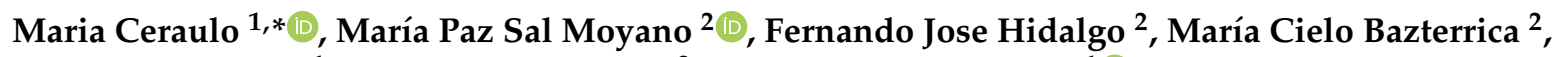 \\ Salvatore Mazzola ${ }^{1}$, María Andrea Gavio ${ }^{2}$ and Giuseppa Buscaino ${ }^{1}$ (D) \\ 1 Institute of Anthropic Impact and Sustainability in Marine Environment (IAS) —CNR National \\ Research Council, Via del Mare 3, 91021 Torretta Granitola (TP), Italy; salvatore.mazzola@cnr.it (S.M.); \\ giuseppa.buscaino@cnr.it (G.B.) \\ 2 Instituto de Investigaciones Marinas y Costeras, Consejo Nacional de Investigaciones Científicas \\ y Técnicas-Universidad Nacional de Mar del Plata, 7600 Mar del Plata, Argentina; \\ salmoyan@mdp.edu.ar (M.P.S.M.); fhidalgo@mdp.edu.ar (F.J.H.); cielobazterrica@gmail.com (M.C.B.); \\ agavio@gmail.com (M.A.G.) \\ * Correspondence: maria.ceraulo@ias.cnr.it; Tel.: +39-3771478356
}

Citation: Ceraulo, M.; Sal Moyano, M.P.; Hidalgo, F.J.; Bazterrica, M.C.; Mazzola, S.; Gavio, M.A.; Buscaino, G. Boat Noise and Black Drum Vocalizations in Mar Chiquita Coastal Lagoon (Argentina). J. Mar. Sci. Eng. 2021, 9, 44. https://doi.org/10.3390/ jmse 9010044

Received: 6 October 2020 Accepted: 29 December 2020 Published: 4 January 2021

Publisher's Note: MDPI stays neutral with regard to jurisdictional clai$\mathrm{ms}$ in published maps and institutional affiliations.

Copyright: $@ 2021$ by the authors. Licensee MDPI, Basel, Switzerland. This article is an open access article distributed under the terms and conditions of the Creative Commons Attribution (CC BY) license (https:// creativecommons.org/licenses/by/ $4.0 /)$.

\begin{abstract}
Human-generated underwater noise and its effect on marine biota is recognized as an important issue. Boat noise can affect the communication success of fish species that use sounds for spawning purposes. During the reproductive period, males of the black drum Pogonias spp. produce calls ranging from $90 \mathrm{~Hz}$ to $300 \mathrm{~Hz}$. In the Mar Chiquita coastal lagoon (Buenos Aires, Argentina), Pogonias courbina is one of the primary fishing species. Although no regulation is directly applied to protect it, a ban protects the reproductive period of other fish species during weekdays. Here, we investigated the potential effect of boat noise on P. courbina vocalizations through a passive acoustic method. Acoustic data were collected, and P. courbina calls were identified and counted. The files with boat noise passages were categorized into classes according to their noise frequency range ( $\mathrm{A}$ = below $700 \mathrm{~Hz}, \mathrm{~B}=$ over $700 \mathrm{~Hz}$, and $\mathrm{C}$ = below and above $700 \mathrm{~Hz}$ ). The fish call rate was lower in files where boat noise overlapped the fish call frequency (Classes A and C). Only boat noise from Class $C$ was significantly reduced during days with the active fishing ban. These results suggest that anthropogenic noise may affect the P. courbina call rate and underline the importance of including the evaluation of anthropogenic noise in the current management of the area.
\end{abstract}

Keywords: black drum; call rate; fish; pollution; shipping noise

\section{Introduction}

Growing human density in coastal habitats is leading to increased anthropogenic pollution, among which are increasing levels of human-generated noise in underwater habitats. Its effect on animal assemblages is an important problem for the community [1-6]. Human noise can affect the health and well-being of aquatic animals, from mammals [7-9] to invertebrates [10-12], leading to physiological and behavioral changes. The response to noise occurs through adaptation or avoidance strategies [13-17]. The responses can be different at the species level, and little is known about them for many species.

Sciaenidae is an important teleost family that comprises about 270 species [18,19]. They are known as croakers and drums for their extensive use of sounds to communicate [20]. The sounds produced are generally composed of trains of pulses, with a frequency range between $100 \mathrm{~Hz}$ and $1000 \mathrm{~Hz}$ and little modulation [20]. The calls have been classified as reproductive and disturbance calls. Reproductive calls are emitted during the spawning season by males, with a general increase during night hours [21,22].

Black drum Pogonias spp. are distributed along coastal waters in both the northwest and southwest areas of the Atlantic Ocean. They have been recently redescribed based on molecular and morphologic evidence, differentiating the black drum Pogonias courbina 
of the southwest Atlantic Ocean from the black drum Pogonias cromis of the northwest Atlantic Ocean [23]. In Argentina, P. courbina is the largest sciaenid noted in estuarine environments [24]. This species is considered a multiple spawner, forming reproductive aggregations in depths of less than $10 \mathrm{~m}$ mainly from October to December (spring season in the Southern Hemisphere) [24]. The dimensions of spawning aggregations, combined with their fishery values [25], have caused increased commercial and recreational fishing pressure on this species [26]. Pogonias courbina is considered the most endangered sciaenid in the southwestern Atlantic Ocean, classified as endangered in Brazil, Uruguay, and Argentina by the International Union for Conservation of Nature Red List (IUCN 2018) [23].

The spawning activity of these species is connected to the production of drumming sounds as advertisement calls emitted by males. Since egg density and call intensity were not found to be synchronous in Pogonias cromis, it was suggested that the calls are emitted for a territorial purpose or to attract females and maintain their spawning conditions [27]. Pogonias cromis calls are characterized by a fundamental frequency of $94 \mathrm{~Hz}$, followed by two harmonics at $188 \mathrm{~Hz}$ and $282 \mathrm{~Hz}$, with an average source level estimate of $165 \mathrm{~dB} \mathrm{RMS}_{\mathrm{R}}$ re: $1 \mu \mathrm{Pa}[22,28]$. Tellechea et al. [29] described the signals emitted by black drum fish from the Southern Hemisphere and found differences from the northern species in terms of the duration of calls. The P.cromis acoustic system is characterized by a swim bladder relatively distant from the otic capsule, and it responds to sounds from $100 \mathrm{~Hz}$ to $800 \mathrm{~Hz}$, with the most sensitive range from $100 \mathrm{~Hz}$ to $600 \mathrm{~Hz}$ [30]. The communication range of black drum fish was estimated at 33-108 m, limited by background levels, not by auditory sensitivity [28]. The spawning period of both the southern and northern black drum species lasts for several days [24,31] and, at least for P. cromis, the chorus start time is regulated by the photoperiod and temperature [31]. Though different aspects of P. cromis and P. courbina reproduction and seasonal variability have been reported [24,32], no information is available on the relationship with salinity and temperature or the impact of human-induced disturbances on their reproductive output.

Human pressure during the reproductive season of fish can act directly not only through harvesting activities, but also through other disturbance factors. It has been recognized worldwide that boat noise can affect animal behavior, health, communication efficiency, and fitness [5,10-12,33-36]. Particularly for fish species that utilize acoustic communication for spawning purposes, boat-related noise can lead to a reduction of successful reproductive events, threatening their populations' survival [37-39]. The few studies focused on the direct effects of boat noise on acoustic emissions showed different responses among fish species. For example, Sciena umbra and Cyprinella venusta showed compensation behavior during noise conditions, increasing the number of pulses after continuous boat passages $[40,41]$. On the contrary, the males of two gobies species (Gobiusculus flavescens and Pomatoschistus pictus) showed a reduction in the number of vocalizations when exposed to continuous noise [42]. In Pogonias cromis, boat noise can overlap in frequency and time with the vocalizations [37]. However, the possible effect of boat noise on acoustic emission has not yet been investigated.

The Southwest Atlantic Mar Chiquita lagoon $\left(37^{\circ} 40^{\prime} \mathrm{S}, 57^{\circ} 23^{\prime} \mathrm{W}\right)$ is a unique coastal lagoon in Argentina which is permanently connected to the sea [43]. It is a Man and the Biosphere (MAB) reserve (United Nations Educational, Scientific and Cultural Organization -UNESCO [44]) where there is an effort to maintain a balanced relationship between social economic development (such as tourism and recreational fishing) and the conservation of nature [45]. The Mar Chiquita coastal lagoon is protected by different legal entities of municipal, provincial, national, and international management. The most intense human pressures in the lagoon are related to recreational activities, such as kite surfing, kayaking, and fishing [45]. Target species for recreational fishing are the silverside Odontesthes spp., flounder Paralichthys orbignyanus, and P. courbina, the only sonic species [46,47]. During the reproductive period of Odontesthes spp., a ban of fishing activities during weekdays (Monday to Friday), from September 1 to December 1 every year, is imposed by Provision 
No. 89/08 of the Ministry of Agrarian Issues of the Buenos Aires Province. However, no regulation is directly applied to protect the other fish species.

Despite the number of publications on the local fish community (e.g., $[46,48,49])$, few studies have been carried out on the acoustic activity of species in the area [50,51]. A previous study [52] investigated the lagoon soundscape and its variations from the mouth to the inner side of the lagoon, revealing the highest presence of black drum mating calls in the mouth of the lagoon and during the month of November. Moreover, results showed that this part of the lagoon was the most affected by boat noise in the same period, highlighting the need to further investigate the possible implications.

For this reason, the aim of this study was to evaluate the following:

(1) The level of boat noise in the mouth of the lagoon;

(2) The temporal overlapping of black drum sounds and boat noises in the mouth of the lagoon;

(3) The potential effect on black drum acoustic activity;

(4) The effectiveness of the fishing ban on boat noise in the mouth of the lagoon.

\section{Materials and Methods}

\subsection{Study Area}

The Mar Chiquita (Buenos Aires, Argentina) coastal lagoon is connected to the sea through an inlet channel $6 \mathrm{~km}$ long and about $200 \mathrm{~m}$ wide (Figure 1) [43,53].

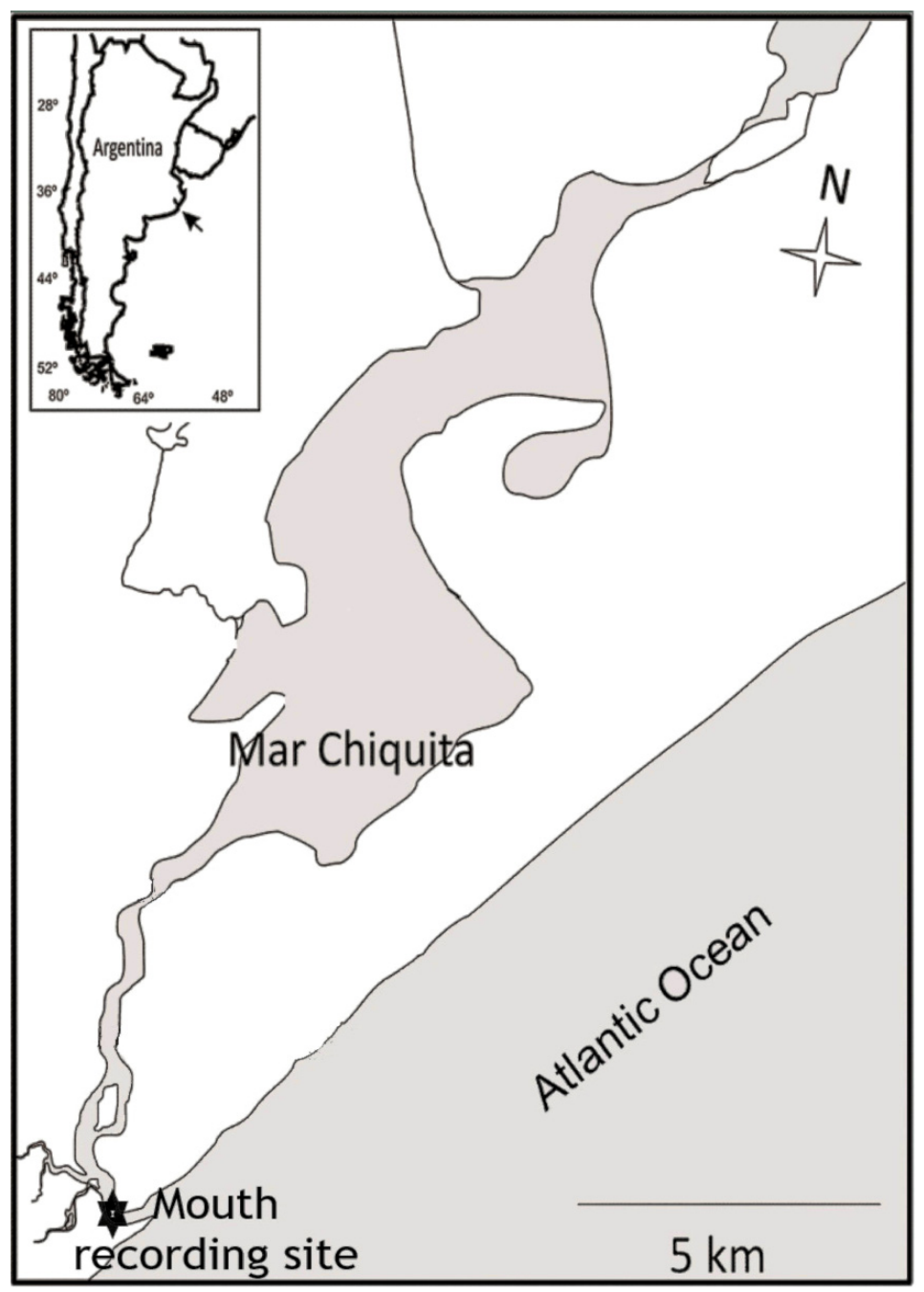

Figure 1. Map of the study site. Star indicates recording site, close to the mouth of the lagoon. The map is modified from Bazterrica et al. 2014 [54], in agreement with Bazterrica M.C. 
The environmental characteristics of the lagoon change from the mouth to the headlands, being comparable to the coastal sea area in the mouth and influenced by the freshwater conditions in the headlands [53]. The depth of the lagoon in the estuarine region is typically $1.5-2 \mathrm{~m}$, while it reaches $3 \mathrm{~m}$ in the discharge channel in the mouth $[43,55,56]$.The lagoon has important conservation value for its unique ecosystem (classified by the MAB Programme by UNESCO [44]). Here, the black drum is among the primary fished species, due to its size and flesh quality [47]. It is an estuary-dependent marine fish, abundant in the mouth of the lagoon during the autumn, spring, and summer [49]. Vessels in the lagoon are represented by small boats, with lengths less than $4 \mathrm{~m}$, equipped with a small outboard engine and adapted to move around in the shallow waters of the estuarine region, mostly using the deeper central area of the lagoon.

\subsection{Data Collection}

Data were collected with an autonomous recorder deployed close to the mouth of the lagoon $\left(37^{\circ} 44^{\prime} \mathrm{S}, 57^{\circ} 25^{\prime} \mathrm{W}\right)$. The recorder was vertically attached to a semi-buried metal stake and firmly secured by plastic zip ties to avoid any vibration. In order to be underwater for the entire sampling time, the hydrophone was positioned during low tide conditions at a water depth of $70 \mathrm{~cm}$ at the site of deployment, remaining at $30 \mathrm{~cm}$ from the bottom of the lagoon. The deployment site was $15 \mathrm{~m}$ from the coast side and about $90 \mathrm{~m}$ from the central and deepest part of the lagoon, where vessels pass by more frequently.

The recorder (Lunilettronik, Italy) consisted of an omnidirectional, preamplified, calibrated hydrophone with a flat sensitivity response of $-174.5( \pm 2) \mathrm{dB}$ re $\mathrm{V} / \mu \mathrm{Pa}$ from $0.1 \mathrm{~Hz}$ to $70 \mathrm{kHz}$ (Benthowave BII 7016 T6 low-noise broadband hydrophone) and a digital signal processor (C5535 DSP-TMS320C5535) coupled with an AIC3204 audio codec (Texas Instruments). The recordings were carried out using a sample frequency of $192 \mathrm{kHz}$ at 16 bits, alternating between $2 \mathrm{~min}$ of recordings and $8 \mathrm{~min}$ of pause (duty cycle of $20 \%$ ). Data were collected in November (spring season) during 3 sessions of 5 days each. Each session covered both weekdays and weekends, with and without the fishing ban, respectively (Table 1). The water temperature was recorded with the temperature sensor of the hydrophone during the sampling period.

Table 1. Data collection following a duty cycle of $2 \mathrm{~min}$ of recording and $8 \mathrm{~min}$ of pause.

\begin{tabular}{cccccc}
\hline $\begin{array}{c}\text { Recording } \\
\text { Sessions }\end{array}$ & Start Time & End Time & $\begin{array}{c}\text { Recordings without } \\
\text { Fishing Ban }\end{array}$ & $\begin{array}{c}\text { Recording with } \\
\text { Fishing Ban }\end{array}$ & Total Recording \\
\hline & & & Number of Days (minutes) & Number of Days (minutes) & Minutes \\
\hline 1 & $01 / 11 / 201714: 00$ & $06 / 11 / 201711: 20$ & $2(240)$ & $4(420)$ & 660 \\
2 & $11 / 11 / 201701: 00$ & $15 / 11 / 201717: 50$ & $2(268)$ & $3(348)$ & $3(336)$ \\
3 & $18 / 11 / 201712: 00$ & $23 / 11 / 201707: 10$ & $3(364)$ & 10 & 700 \\
\hline & Total Days of & 7 & & \\
\hline
\end{tabular}

\subsection{Sound Analysis}

Using iZotope RX software, the dataset was aurally and visually inspected through a spectrogram survey, using a logarithmic frequency scale to obtain preliminary identification of the different sound sources, exclude files with noises conceivably generated by crustaceans touching the hydrophone, and identify and classify files with boat noise.

To quantify the potential impact of boat noise, files with boat passages were visually and aurally identified in the spectrogram. A preliminary screening highlighted the presence of different types of boat noise, as found by Smott et al. [37] while investigating the anthropogenic component of the May River estuary (South Carolina, USA) soundscape. All files containing boat noise were categorized into three classes, based on the noise frequency range extension (Figure 2a,c): 
1. Class A: narrow band noise, with low frequency noise in a range below $700 \mathrm{~Hz}$;

2. Class B: mid-frequency noise, with mid-to-high frequency noise in a range over $700 \mathrm{~Hz}$;

3. Class C: burst broadband noise, with the entire band noise covering the entire spectrum (below and above $700 \mathrm{~Hz}$ ).

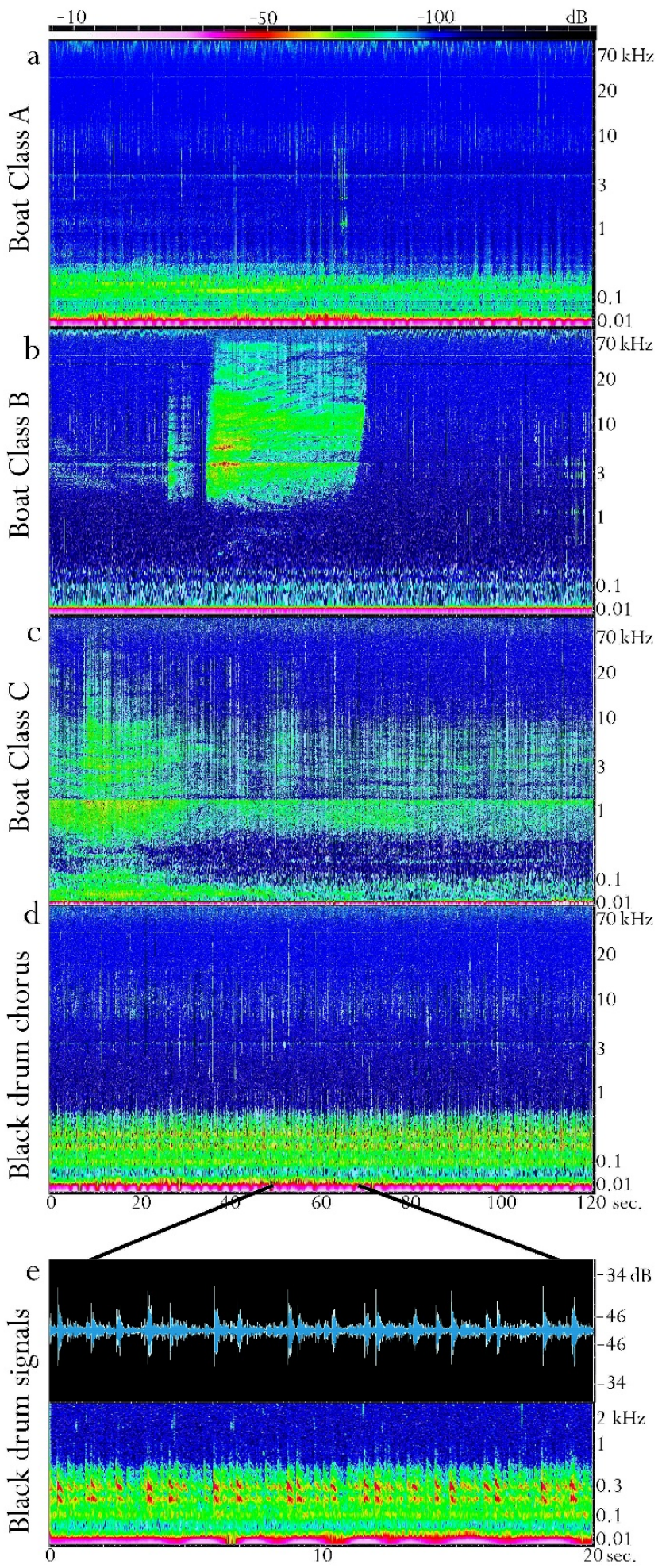

Figure 2. Spectrograms (sampling frequency $=192 \mathrm{kHz}$, FFT size $=16,384$, Hamming windows) of 120 s of recordings with: (a) boat noise of class A; (b) boat noise of class B; (c) boat noise of class C; (d) black drum chorus. In (e) a zoomed portion (20 s) of spectrogram and waveform of black drum signals. The frequency is on a logarithmic scale. 
All files without boat noise were included in a fourth class: Class $\mathrm{N}$.

Noise classes can be related to the velocity of traveling boats [57] and the use of particular engines [58]. The categorization was deemed important and retained for this study since, from the black drum audiogram, this species ended up being less sensitive to noise over $600 \mathrm{~Hz}$ [30].

Based on previous descriptions of black drum signals [22,28,29], the recorded P. courbina calls were identified as loud drum sounds emitted during courtship behavior by males before spawning (Figure 2d,e).

In order to evaluate the overlapping frequencies between fish sounds and different kinds of boat noise, for each 2 min file with the presence of only boat noise, fish chorus, and background noise, the average power spectrum was calculated.

The count of single drum calls was carried out by combining automatic and manual analysis. First, all acoustic files were downsampled from $192 \mathrm{~Hz}$ to $6 \mathrm{kHz}$. Using the merge function of Avisoft SASlab Pro software (Avisoft-SASLab Pro-Avisoft Bioacoustics), one daily file at the start and end of the chorus was generated. In order to isolate the calls from the noise, a band pass filter from $0.1 \mathrm{kHz}$ to $0.7 \mathrm{kHz}$ was applied to these files, and each call was automatically counted using the pulse train analysis with labelled output function of the software. After preliminary tests, the following parameters were empirically set and maintained for the analysis of the entire data set: time constant $50 \mathrm{~ms}$, threshold $0.17 \mathrm{~Pa}$, hysteresis $5 \mathrm{~dB}$, start and end threshold $-1 \mathrm{~dB}$. The pulse train analysis automatically counted and marked every single call in the waveform that overpassed the fixed energy threshold. This parameter is not adaptive to background noise, so that made it possible to count the signals during intense chorus activity, but it did not increase during boat noise passages or windy conditions. On the one hand, this did not affect the sensitivity of the method when there was a lot of background noise, but on the other hand, water or boat noise could be incorrectly detected, leading to false positive errors (see Figure 3). For this reason, manual and automatic analysis were combined.

All the recordings were visually checked by an expert operator, and false positive errors due to the automatic counting during noise emission were adjusted (see Figure $3 \mathrm{~g}$ ).

If boat noise was so intense as to prevent the identification of black drum calls, that section of the recordings was excluded from the data set. In total, $1.3 \mathrm{~min}(3 \%)$ of recordings were excluded from the data set. In all the other cases, the intensity of the calls was intense enough to make them identifiable in the waveform by the pulse train count (see Figure 3e-h). The intensity of the fish call (see the result section of Figure 4), combined with the used acoustic filter, led to supporting the correct assessment of call numbers during Class $\mathrm{A}$ and $\mathrm{C}$ boat noise as well. 

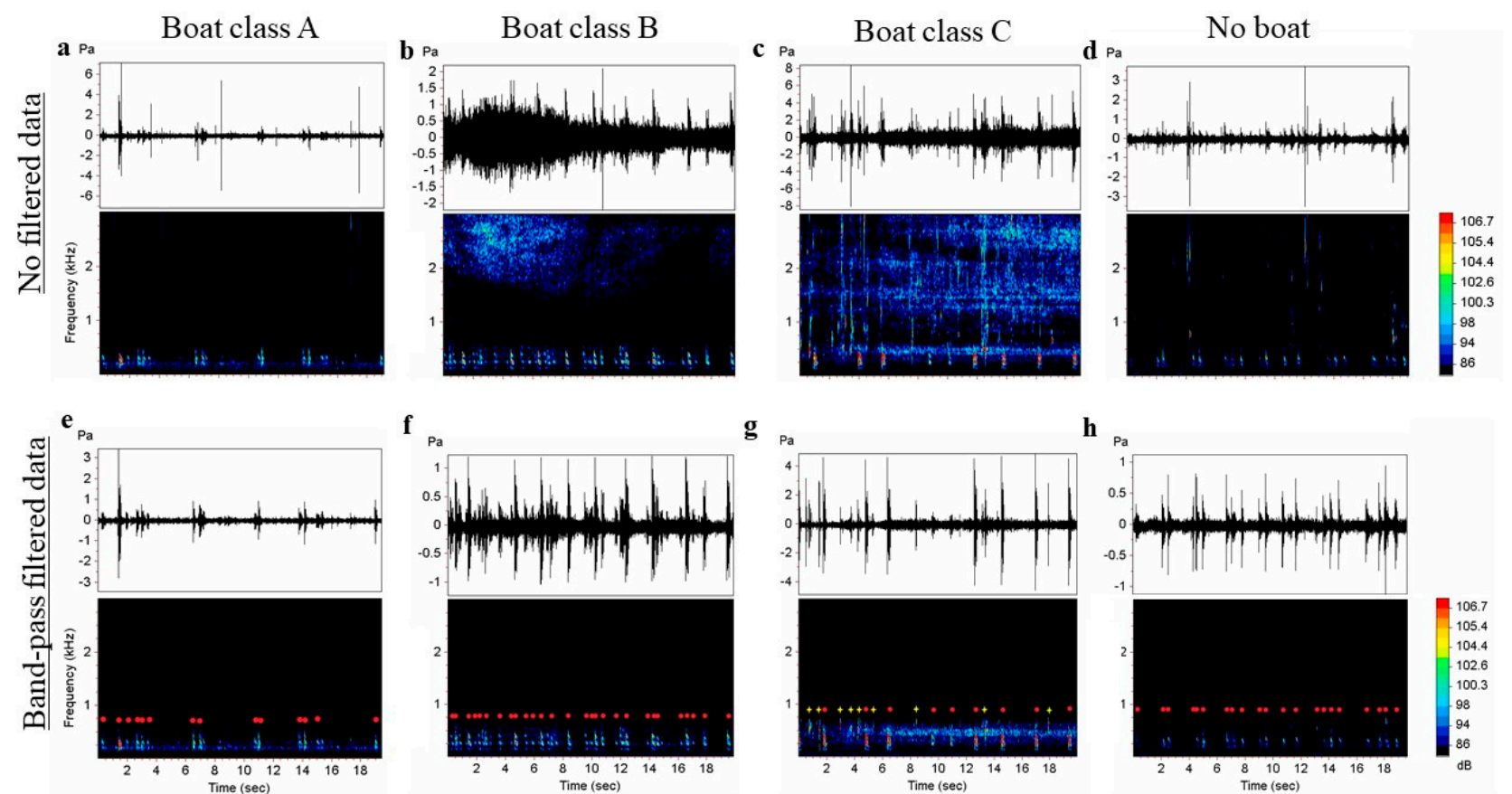

Figure 3. Spectrograms (FFT size $=512$, Hamming windows) and waveform of $20 \mathrm{~s}$ of recording subsampled at $3 \mathrm{kHz}$, with black drum calls during Class A boat noise, Class B boat noise, Class $\mathrm{C}$ boat noise, and no boat noise without a band filter (from (a) to (d)) and 0.1-0.7 kHz of band-pass filtering (from (e) to (h)). Red dots indicate calls correctly counted by automatic pulse train analysis; yellow stars indicate signals wrongly detected by automatic counting and excluded by visual inspection.

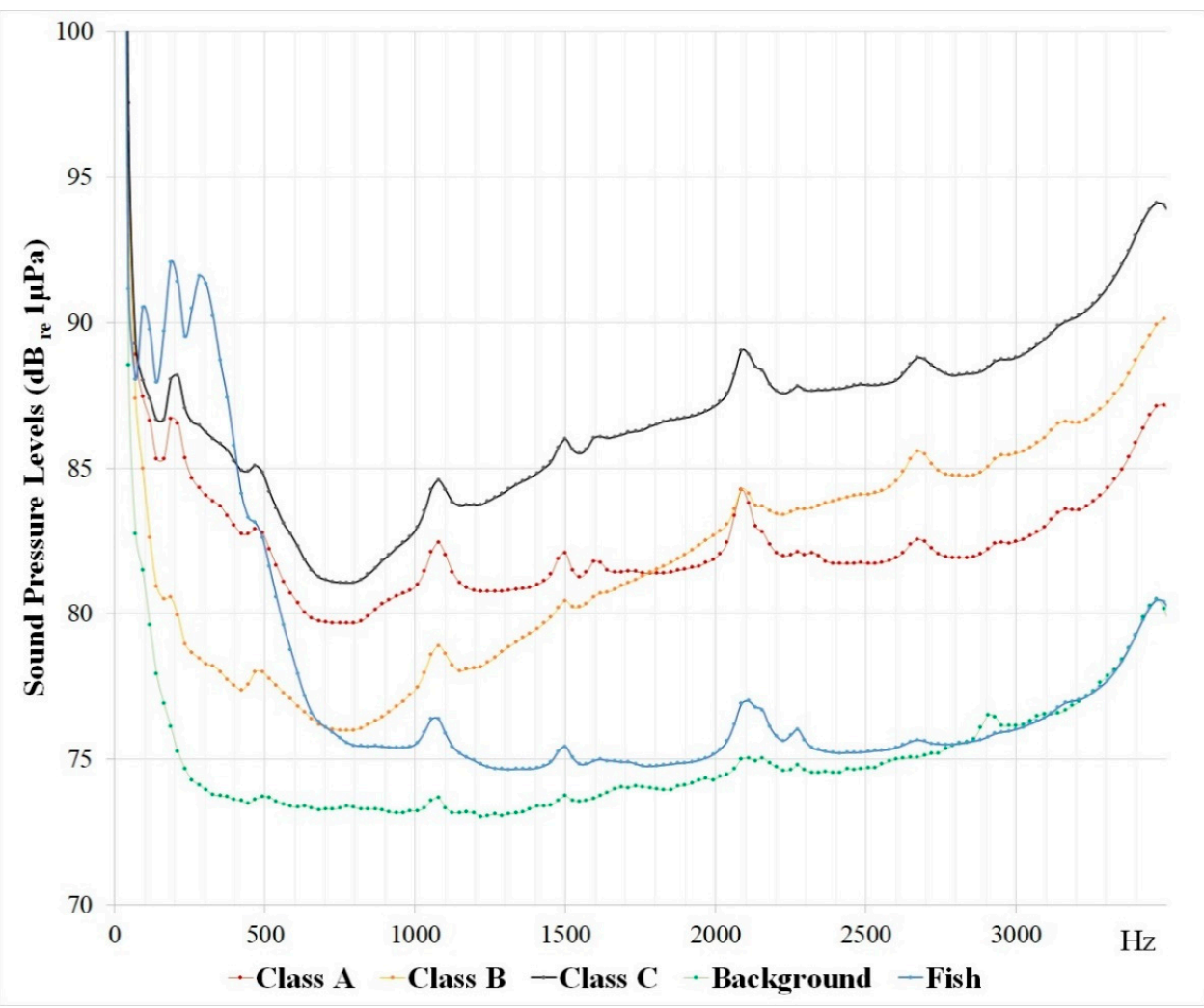

Figure 4. Averaged sound pressure level ${ }_{\text {rms }}$ (sampling frequency of $192 \mathrm{kHz}$; frequency resolution of $23.4 \mathrm{~Hz}$; Hamming window; and FFT size of 8192 points) of all files with Class A (red), Class B (orange), and Class C (dark gray) boat noise, fish chorus (blue), and background noise (green). 
In order to normalize the data, the black drum call rate parameter was measured, dividing the number of counted calls by the duration in seconds of the analyzed recording:

$$
\text { Black drum call rate }=\frac{\text { Number of calls counted for file }}{\text { duration }(s) \text { of analysed recording }}
$$

To evaluate if the presence of different kinds of boat noise could affect the black drum call rate while also considering possible variability due to the different daily environmental conditions and the time of day, linear mixed models (LMMs [59]) were carried out, including the data where fish calls were recorded (black drum call rate $>0$ ) as a dependent variable and the boat type variable (Class A, Class B, Class C, or Class N) as a possible explicative factor. The day and hours factors were included and tested as possible random factors, either individually or combined. A Gaussian family distribution and identity link function were chosen. The best fit model was selected by means of model averaging, based on the Akaike information criterion (AIC). Validation graphs (e.g., plots of observed versus predicted values, the residuals versus predicted values, and normal quantile-quantile $(\mathrm{Q}-\mathrm{Q})$ ) were analyzed to control for possible model misspecification and the presence of outliers (see Figure A1).

Moreover, considering only files where fish calls were detected, the Pearson's correlation between the black drum call rate and the temperature was calculated.

Finally, to understand if the boat noise recorded in the lagoon was affected by the fishing ban, the daily average of the boat recordings was calculated as follows:

Daily average of boat presence $=\frac{(\text { sum of daily number of files with presence of boat noise by class })}{n u m b e r \text { of daily files }}$

The values calculated during the days with and without the fishing ban were compared using the Mann-Whitney $U$-test.

\section{Results}

In total, 2063 files of 2 min each were recorded. Boat noise was recorded in 550 files (27\%); in particular, 163 files were categorized as Class A noise, 133 as Class B, and 251 as Class C. Fish sounds were recorded in 188 files.

The most intense noise was generated by the boats in Class $\mathrm{C}$, resulting in an average increase of $11.8 \mathrm{~dB}( \pm 1.83 \mathrm{~dB})$ from $70 \mathrm{~Hz}$ to $3800 \mathrm{~Hz}$ compared with the background noise. Boats in Classes $A$ and $B$ were less intense, with an average noise increase of $7.46 \mathrm{~dB}$ $( \pm 1.06 \mathrm{~dB})$ and $7.22 \mathrm{~dB}( \pm 2.61 \mathrm{~dB})$, respectively, in the same frequency range. The fish chorus resulted in an increase in energy of about $11.35 \mathrm{~dB}( \pm 4.16 \mathrm{~dB})$ from $70 \mathrm{~Hz}$ to $600 \mathrm{~Hz}$. In this frequency range, the average increase of $S P L_{r m s}$, determined by the boat noise of Class C, was $10.64 \mathrm{~dB}( \pm 1.86 \mathrm{~dB})$, whereas for Class A it was $8.86 \mathrm{~dB}( \pm 1.49 \mathrm{~dB})$ and for Class B it was only $4.01 \mathrm{~dB}( \pm 0.46 \mathrm{~dB})$ (Figure 4$)$.

Fish and boat noises were recorded during the whole sampled period. The black drum chorus generally started at 5:00 p.m. and continued throughout the night. Boat noise and black drum calls were recorded simultaneously for $12.8 \%$ of the data collected and $17 \%$ of the chorus time emission (Figure 5). 


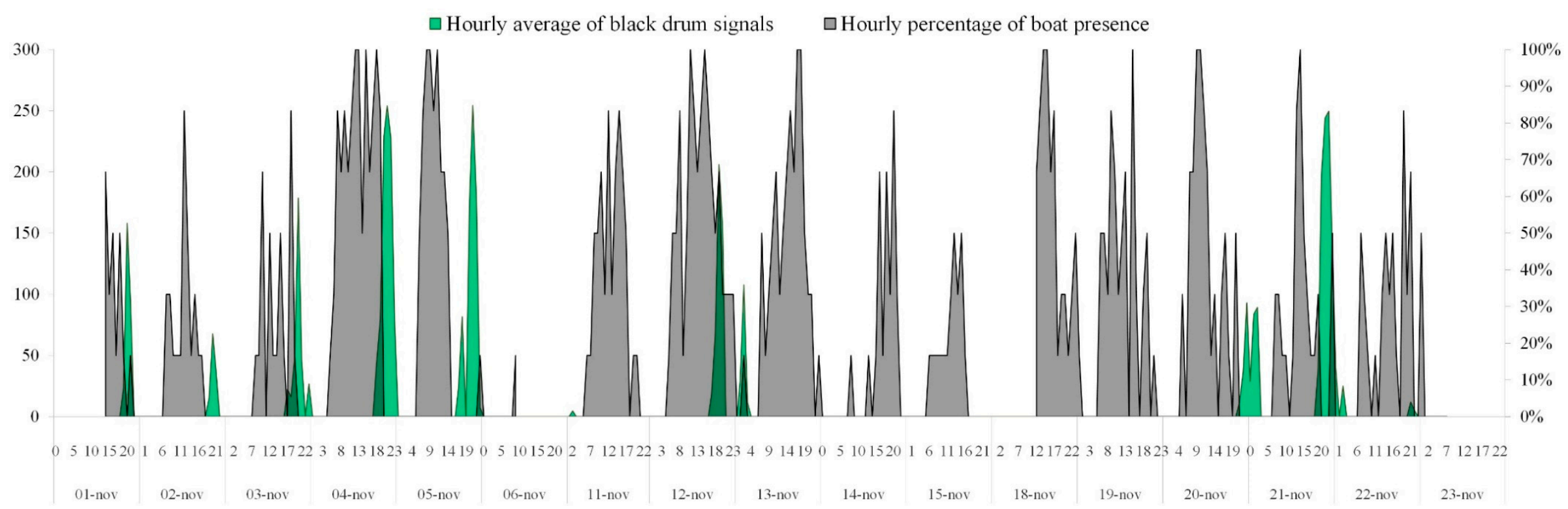

Figure 5. Hourly percentage of boat noise present (right axis, gray area) and hourly average of black drum signals (left axis, green area) for the entire sampling period. 
The best linear mixed model (LMM) selected included both the hour and day variables as random factors. The observed vs. predicted values, the residuals vs. predicted values, and the normal $\mathrm{Q}-\mathrm{Q}$ plots are reported in Figure A1.

The presence or absence of boats significantly affected the number of fish signals (ANOVA: $\mathrm{F}=5.55, \mathrm{df}=3, p<0.01$, shown in Figure 6).

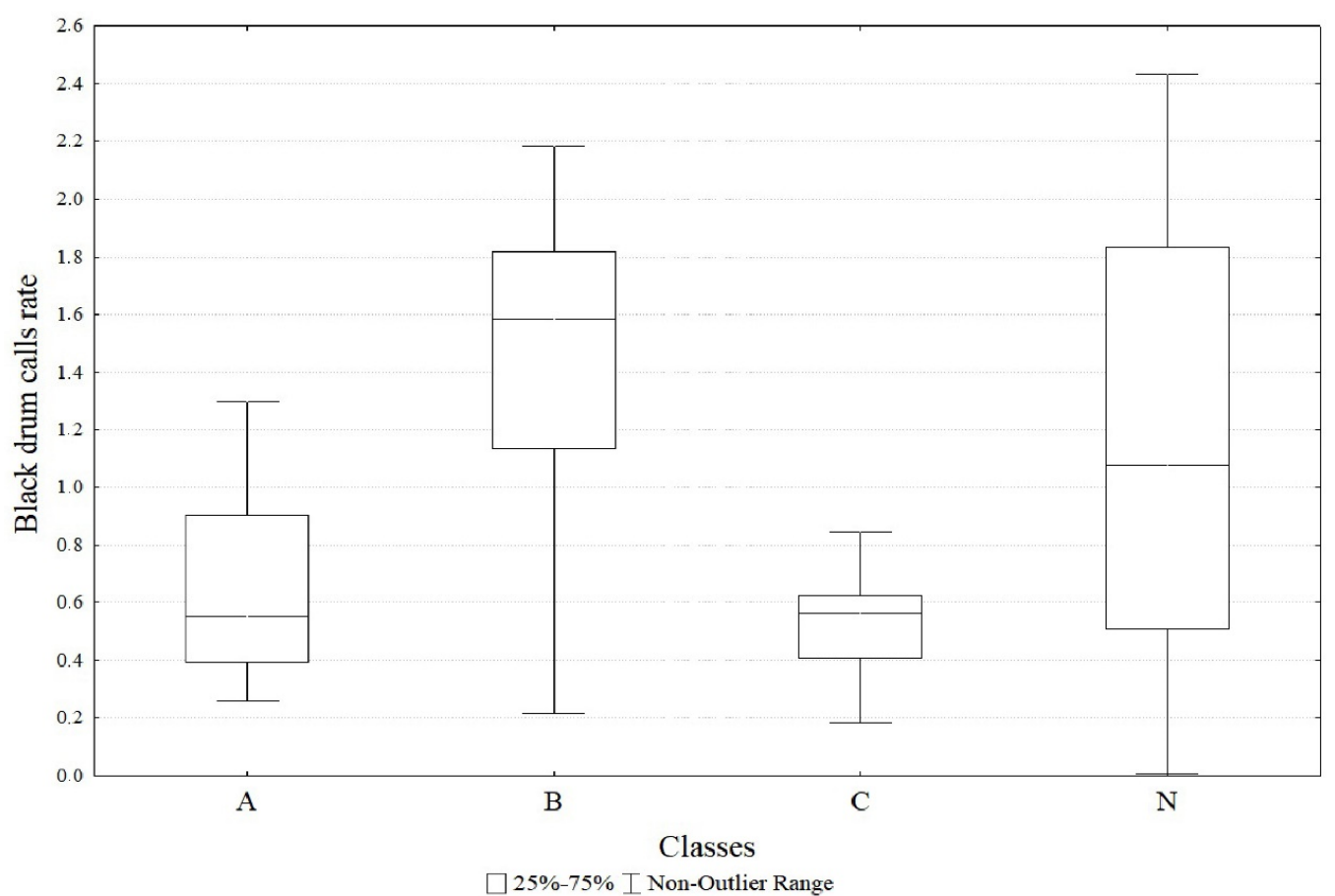

Figure 6. Boxplot of black drum call rates in the absence of boat noise (class N) and during boat noise of Classes A, B, and C. The line indicates the median, the box indicates the 25 th-75th percentile, and the buffers indicate the non-outlier range.

The estimated variation of the call rate for different classes of boat noise with respect to the absence of boat noise is reported in Table 2. There was a total of 561 calls for Class A, 1857 for Class B, 323 for Class C, and 22,862 for Class N.

Table 2. Results of the linear mixed model (LMM) on black drum call rates among the absence of boat noise (Class N) and the presence of noise from Classes A, B, and C, considering the day and hour variables as random factors.

\begin{tabular}{cccccc}
\hline & & Estimate & Standard Error & Z Value & $p$ Value \\
\hline Black drum call rate & (Intercept) & 0.89 & 0.16 & 5.49 & $<0.0001$ \\
& Class A & -0.46 & 0.23 & -1.99 & $<0.05$ \\
& Class B & 0.22 & 0.19 & 1.17 & 0.24 \\
& Class C & -0.83 & 0.24 & -3.39 & $<0.001$ \\
\hline
\end{tabular}

The presence of Class A and C boat noise resulted in a significant reduction of the black drum call rate. In particular, the effect was higher with the presence of Class $C$ noise (Table 2).

The temperature in the sampled period ranged from $14.8{ }^{\circ} \mathrm{C}$ to $22.6{ }^{\circ} \mathrm{C}$. The Pearson's correlation was not significant between the number of signals and the water temperature $(\varrho=0.108, p=0.141)$.

The comparison of the daily average of boat recordings in the presence and absence of the fishing ban showed a significant reduction for the boat noise of Class $\mathrm{C}$ during the ban (Mann-Whitney $U$-test: $Z=-3025, p<0.01$ ) and no differences for the other boat noise classes (Figure 7). 


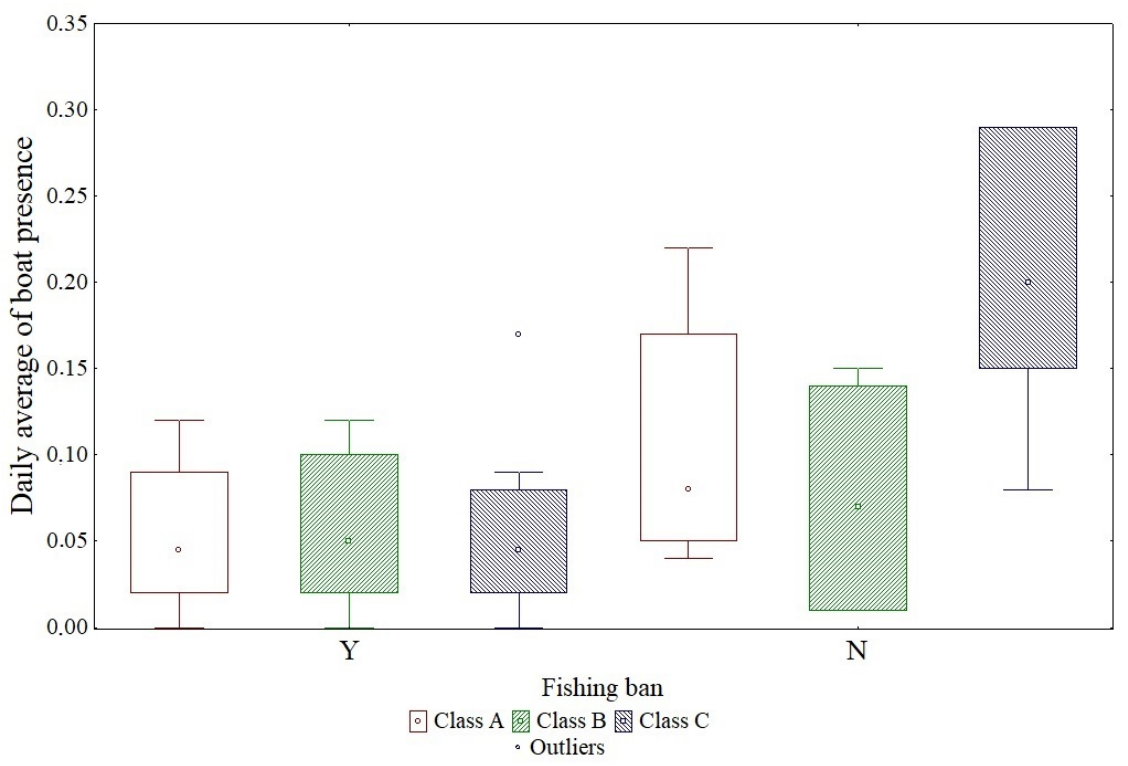

Figure 7. Box plot of daily average boat presence on days with and without a fishing ban. The square indicates the median, the box indicates the 25th-75th percentile, and the buffers indicate the non-outlier range.

\section{Discussions}

This work described and quantified the level of boat noise in the mouth of the Mar Chiquita coastal lagoon, a Man and the Biosphere reserve, in the presence and absence of a fishing ban and evaluated the possible effect of boat noise on the chorus vocalizations of an important local fish species, the black drum. Our results showed that in the presence of boat noise that overlapped the emissions of fish calls and the hearing frequency range of the species, the black drum call rate was lower. The fishing ban led to a significant reduction of only the most intense boat sounds, but it did not affect other kinds of boat noise. Our results suggest that boat noise might affect the Pogonias courbina call rate and that an evaluation of the impact of anthropogenic noise would be important to improve management efforts in the lagoon.

The boat noise recorded in the lagoon during the spring season accounted for $27 \%$ of the time sampled, and it was divided into three classes based on the frequency extension in the spectrogram. The SPL $\mathrm{L}_{\mathrm{rms}}$ measurements in the most sensitive frequency band of black drum fish showed that boat noise extending along the entire frequency band (Class $\mathrm{C}$, defined as burst broadband) was the most intense, while low-frequency (Class A, defined as narrowband) and mid-frequency (Class B) noise was less intense.

Li et al. [57] showed that the frequency ranges of boat noise depend on the velocity of travel; high-speed boats generated burst broadband noise up to $180 \mathrm{kHz}$, with greater components in the mid- to high-frequency ranges, while low-frequency boat noise was associated to a boat traveling at a slow speed or idling [37]. Basing on these data, recordings in the Mar Chiquita lagoon of Classes A and C could represent boats with different velocities in the area. The mid-frequency class (Class B), on the contrary, was less intense than the others below $1500 \mathrm{~Hz}$, but over this frequency, its energy increase became higher than the noise from Class A. This suggests an association of this noise with specific kinds of boats more than their travel patterns, particularly watercraft or small boats with outboard or inboard engines [58]. The boats used inside the lagoon are mostly small (less than $4 \mathrm{~m}$ with a little outboard engine, generally $10 \mathrm{HP}$ ), but some bigger ones (about $6 \mathrm{~m}$ with $60 \mathrm{HP}$ engines) can be used in the inlet to fish out of the lagoon. Nevertheless, Mar Chiquita is characterized by shallow water conditions with a mean depth of less than $1 \mathrm{~m}$ [43], and the recorded mid-frequency boat noise could have been the result of a combination of particular vessel propellers and high-pass filter action due to the low depth $[4,60]$. 
The black drum signals recorded in Mar Chiquita showed three frequency peaks (94, 210, and $280 \mathrm{~Hz}$ ) matching those described in [31]. On the contrary, the calls described by Tellechea et al. [29] for the southern species showed a fundamental frequency of about $135 \mathrm{~Hz}$. The reason for this mismatch could be related to the length of the specimens or to propagation conditions in the studied area, and this needs to be deeply investigated. The black drum chorus in the lagoon was very intense, and the average SPL $\mathrm{L}_{\mathrm{rms}}$ recorded achieved comparable values to noisier boats. On the contrary, Smott et al. [37] found that the energy levels measured from Class $C$ and $B$ boats were above the power spectral density of the black drum chorus measurements in the May River estuary, suggesting that these two noise classes could increase the risk of auditory masking (defined as interference in the perception of important sounds by others, influencing detection, discrimination, and signal recognition [61]). Our results could be due to the relative distances of fish and boat sources from the hydrophone deployment site, which was located closer to the coastline than to the middle of the lagoon, an area mainly used by boats for transit. Moreover, boats in the area generally move slowly due to the presence of sand banks and the generally low depth. However, the effect of noise on animal communication may be related not only to its amplitude but also to the overlap in frequency between the noise and animal acoustic space [61]. In our work, Class A and class C boat noise showed comparable SPL $L_{\text {rms }}$ values to fish signals, falling in the frequency range used by black drums for their calls $(100-300 \mathrm{~Hz}$ ) and in their most sensitive range (up to $500 \mathrm{~Hz}$ ). On the contrary, Class B showed the same attenuation in the important frequency range of the species for emission as for the perception of acoustic signals. Based on this, it is likely that Class $\mathrm{A}$ and $\mathrm{C}$ boat noise that occurs simultaneously with call emission can affect black drum communication, leading to a masking effect [62].

In the Mar Chiquita coastal lagoon, boat noise reached high levels during the day hours throughout the sampled period, occurring in up to $100 \%$ of the recorded files in some hours. Meanwhile, the fish acoustic activity generally started from 5:00 p.m. The two sounds overlapped for some hours on all days, mostly during sunrise, reaching an almost $17 \%$ co-presence during chorus activity. During this period, our results showed a reduction in the fish call rate in the presence of Class $\mathrm{A}$ and $\mathrm{C}$ boat noise when compared with the no-boat condition. The reduction of calls could indicate a temporary interruption of acoustic behavior and could also be related to animals moving away from the recording area.

The variation in the number of calls did not show a correlation with temperature variation which, in the sampled period, ranged from $14.8^{\circ} \mathrm{C}$ to $22.6^{\circ} \mathrm{C}$, but the analysis could be improved by increasing the length of time for data collection and following the entire mating period.

Several works have shown that fish species modify their behavior when there is boat noise (e.g., foraging [63], predation, and survival [64]), their hearing threshold changes [65,66], and it affects successful mating [61]. The responses differ according to the species, the life stage, and the kind and duration of the stimulus [67-69]. Few studies have focused on vocal communication variations. Picciulin et al. [40] and Holt and Johnston [41] reported that Sciena umbra and Cyprinella venusta, respectively, emitted an increased number of signals during boat noise. This was interpreted as compensation behavior necessary to obtain successful communication in noisy conditions. On the contrary, the reduced emission of courtship drums during continuous noise ( $30 \mathrm{~min}$ of stimulus) by males of two goby species (Gobiusculus flavescens and Pomatoschistus pictus) was found in a controlled tank experiment [42]. In accordance with de Jong et al. [42], our results showed a reduced rate of Pogonias courbina calls during noise emission.

Our results are the first evidence of possible noise effects on P.courbina communication. However, some limitations, due to the use of the passive acoustic method in a natural environment with a non-continuous sampling design, need to be highlighted. Indeed, despite this method giving the opportunity to study animal acoustic behavior without human operator interference, it does not allow for control of some important variables (e.g., fish school size and distance between the black drum fish group and the boat) that 
may affect the fish response to boat noise. The absence of visual observation of boats in the area during the recordings and the use of a single hydrophone did not allow us to exactly match the noise recorded with the different boats moving in the lagoon and to estimate the locations of fish. For this reason, even though the high intensity of fish signals and the use of a conservative approach for the analysis (combining automatic and manual detection of filtered signals and excluding the parts of recordings with intense masking) allowed us to support that our detection capacity was not affected by noise-fish call overlapping, only the information about fish and boat locations could dispel any doubts and confirm our results. Moreover, although the use of a non-continuous sampling design let us consider every boat noise event as independent from the previous one, this limits the possibility to make inferences about changing behavior over time, the relation to prolonged noise exposure, or the duration of the effects once the sound source was no longer present [64]. This point was found to be important for other fish species. For example, Picciulin et al. [40] found that the response of brown meagre to boat noise was not immediate, only starting after some vessel passages. On the contrary, Mauro et al. [69] found that the reaction of Sparus aurata to boat noise was immediate, and it returned to normal levels after prolonged exposure. Future studies using continuous sampling design and lasting the entire mating season will help to better understand boat and fish interactions.

In sonic fish species like black drums, in which males use acoustic signals to attract females for mating, the timing overlap between noise and mating calls and their relative reduction can lead to a decreased effectiveness of courtship behavior, with possible consequences on mating success and population survival. In common goby (Pomatoschistus microps), it was demonstrated that the disturbance effects generated by continuous boat noise could be transferred out to the sound's temporal coincidence, influencing male signal perception from females, increasing female latency in nest inspection and spawning, and decreasing spawning probability [33]. During our study in the Mar Chiquita coastal lagoon, an overlap between boat noise and fish acoustic activity was found at the beginning of the fish's nocturnal acoustic activity and reached $17 \%$ coincidence in chorus activity time. Considering that our study was carried out for only one month of recording, we cannot exclude possible changes in human use of the area and relative fish responses with the onset of mating season.

No previous studies have reported on black drum communication success in the presence of boat noise and the effects on reproduction of this species, and further studies are needed to focus on this aspect, increasing the temporal and spatial scale of analysis and investigating the possible effects on reproductive success of this species to better understand the scale of the phenomenon at a population level.

Considering our results, particular attention needs to be focused on the management of boating activity in the Mar Chiquita coastal lagoon. Our data show that the area is selected as a possible spawning site by male black drums. Even if information about the actual state of reproduction activity in the lagoon is missing, our data suggest that boat noise at least interferes with the reproductive acoustic activity of males of this species. In the area, boat usage is related to recreational fishing, and the impact in terms of noise is concentrated in the mouth of the lagoon, close to the village [52]. This activity is governed by Provision No. 89/08 of the Ministry of Agrarian Issues of the Province of Buenos Aires. The provision, which protects the reproductive period of Odontesthes spp., imposed a partial ban of this species, allowing fishing activities only during weekends (Saturday and Sunday) from September 1 to December 1 every year. From our results, this ban led to a significant reduction of only Class $C$ boat noise in the area and did not affect the other classes of noise. This result needs to be extended by collecting data over a longer period of time, covering the entire ban period, but for now it suggests the need for some mitigation strategies to reduce the impact of noise in the lagoon, at least during black drum reproductive periods. For example, promoting the use of engines with less impact in terms of noise and limiting boating activity during the period of fish acoustic activity could be considered as possible solutions to mitigate the effects. Nowadays, management 
strategies are directed at a species-specific level and are related only to fish activity without considering noise as possible pollutant, with potential effects on multiple species. More data and specific studies on this aspect are needed to study the noise effects on an ecosystem scale. The use of a categorization approach to classify the boat noise can furnish a tool to promote specific management strategies able to support not only species conservation, but also sustainable development of human activities in the area. This is especially important in a Man and the Biosphere reserve, where it aims to establish a balanced human-nature coexistence.

Author Contributions: Conceptualization, M.C.; data curation, M.C.; formal analysis, M.C. and M.P.S.M.; funding acquisition, S.M. and G.B.; investigation, M.C., F.J.H., M.C.B., M.A.G., and G.B.; methodology, M.C.; project administration, G.B.; supervision, S.M., M.A.G., and G.B.; writingoriginal draft, M.C.; writing-review and editing, M.P.S.M., F.J.H., M.C.B., M.A.G., and G.B. All authors have read and agreed to the published version of the manuscript.

Funding: This research was funded by the CAIMAR Joint Laboratory Italy-Argentina (Laboratori Congiunti Bilaterali Internazionali of the Italian National Research Council, 2017-2019) and by the project BOSS, studying bioacoustics and applications for the sustainable exploitation of marine resources (projects of major importance in the Scientific and Technological Collaboration Executive Programs, funded by the Italian Ministry of Foreign Affairs and International Cooperation). Other funding support was provided by the Agencia Nacional de Promoción Científica y Tecnológica (PICT 2015/0699) and the Universidad Nacional de Mar del Plata (EXA 880/18).

Institutional Review Board Statement: Not applicable.

Informed Consent Statement: Not applicable.

Data Availability Statement: The data presented in this study are available on request from the corresponding author.

Acknowledgments: We thank Daniel Blanco, Pablo, Miguel Addino, and Mariana Addino for their essential field support.

Conflicts of Interest: The authors declare no conflict of interest. The funders had no role in the design of the study; in the collection, analyses, or interpretation of data; in the writing of the manuscript, or in the decision to publish the results.

\section{Appendix A}
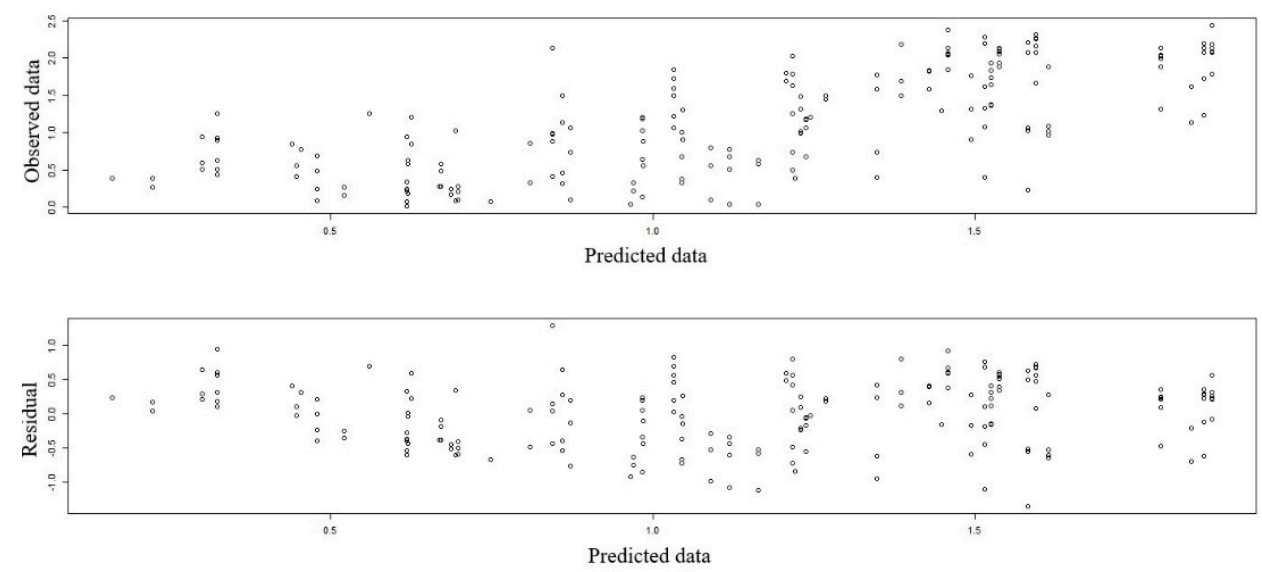

Normal Q-Q plot

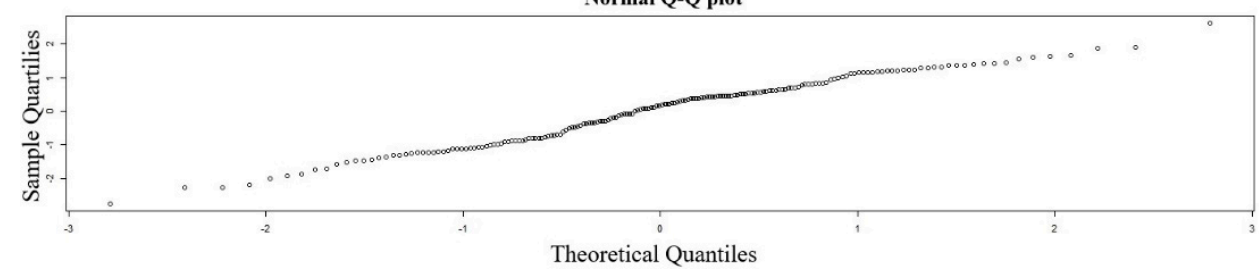

Figure A1. Plots of observed vs. predicted values, residuals vs. predicted values, and normal Q-Q. 


\section{References}

1. Buscaino, G.; Ceraulo, M.; Pieretti, N.; Corrias, V.; Farina, A.; Filiciotto, F.; Maccarrone, V.; Grammauta, R.; Caruso, F.; Alonge, G.; et al. Temporal patterns in the soundscape of the shallow waters of a Mediterranean marine protected area. Sci. Rep. 2016, 6, 34230. [CrossRef] [PubMed]

2. Ceraulo, M.; Papale, E.; Caruso, F.; Filiciotto, F.; Grammauta, R.; Parisi, I.; Mazzola, S.; Farina, A.; Buscaino, G. Acoustic comparison of a patchy Mediterranean shallow water seascape: Posidonia oceanica meadow and sandy bottom habitats. Ecol. Indic. 2018, 85, 1030-1043. [CrossRef]

3. Erbe, C.; Verma, A.; McCauley, R.; Gavrilov, A.; Parnum, I. The marine soundscape of the Perth Canyon. Prog. Oceanogr. 2015, 137, 38-51. [CrossRef]

4. Hermannsen, L.; Mikkelsen, L.; Tougaard, J.; Beedholm, K.; Johnson, M.; Madsen, P.T. Recreational vessels without Automatic Identification System (AIS) dominate anthropogenic noise contributions to a shallow water soundscape. Sci. Rep. 2019, 9, 1-10. [CrossRef] [PubMed]

5. Kunc, H.P.; McLaughlin, K.E.; Schmidt, R. Aquatic noise pollution: Implications for individuals, populations, and ecosystems. Proc. R. Soc. B Biol. Sci. 2016, 283, 20160839. [CrossRef]

6. Williams, R.; Wright, A.J.; Ashe, E.; Blight, L.K.; Bruintjes, R.; Canessa, R.; Clark, C.W.; Cullis-Suzuki, S.; Dakin, D.T.; Erbe, C. Impacts of anthropogenic noise on marine life: Publication patterns, new discoveries, and future directions in research and management. Ocean. Coast. Manag. 2015, 115, 17-24. [CrossRef]

7. Erbe, C. Effects of underwater noise on marine mammals. In The Effects of Noise on Aquatic Life; Springer: Berlin/Heidelberg, Germany, 2012; pp. 17-22.

8. Rolland, R.M.; Parks, S.E.; Hunt, K.E.; Castellote, M.; Corkeron, P.J.; Nowacek, D.P.; Wasser, S.K.; Kraus, S.D. Evidence that ship noise increases stress in right whales. Proc. R. Soc. B Biol. Sci. 2012, 279, 2363-2368. [CrossRef]

9. Wright, A.J.; Soto, N.A.; Baldwin, A.L.; Bateson, M.; Beale, C.M.; Clark, C.; Deak, T.; Edwards, E.F.; Fernández, A.; Godinho, A.; et al. Do Marine Mammals Experience Stress Related to Anthropogenic Noise? Int. J. Comp. Psychol. 2007, $20,274-316$.

10. Buscaino, G.; Filiciotto, F.; Buffa, G.; Bellante, A.; Stefano, V.D.; Assenza, A.; Fazio, F.; Caola, G.; Mazzola, S. Impact of an acoustic stimulus on the motility and blood parameters of European sea bass (Dicentrarchus labrax L.) and gilthead sea bream (Sparus aurata L.). Mar. Environ. Res. 2010, 69, 136-142. [CrossRef]

11. Filiciotto, F.; Vazzana, M.; Celi, M.; Maccarrone, V.; Ceraulo, M.; Buffa, G.; Di Stefano, V.; Mazzola, S.; Buscaino, G. Behavioural and biochemical stress responses of Palinurus elephas after exposure to boat noise pollution in tank. Mar. Pollut. Bull. 2014, 84, 104-114. [CrossRef]

12. Filiciotto, F.; Vazzana, M.; Celi, M.; Maccarrone, V.; Ceraulo, M.; Buffa, G.; Arizza, V.; de Vincenzi, G.; Grammauta, R.; Mazzola, S.; et al. Underwater noise from boats: Measurement of its influence on the behaviour and biochemistry of the common prawn (Palaemon serratus, Pennant 1777). J. Exp. Mar. Biol. Ecol. 2016, 478, 24-33. [CrossRef]

13. Dunlop, R.A.; Noad, M.J.; McCauley, R.D.; Scott-Hayward, L.; Kniest, E.; Slade, R.; Paton, D.; Cato, D.H. Determining the behavioural dose-response relationship of marine mammals to air gun noise and source proximity. J. Exp. Biol. 2017, 220, 2878-2886. [CrossRef] [PubMed]

14. Holt, M.M.; Noren, D.P.; Veirs, V.; Emmons, C.K.; Veirs, S. Speaking up: Killer whales (Orcinus orca) increase their call amplitude in response to vessel noise. J. Acoust. Soc. Am. 2008, 125, EL27-EL32. [CrossRef] [PubMed]

15. Johansson, K.; Sigray, P.; Backström, T.; Magnhagen, C. Stress Response and Habituation to Motorboat Noise in Two Coastal Fish Species in the Bothnian Sea. In The Effects of Noise on Aquatic Life II; Popper, A.N., Hawkins, A., Eds.; Springer: New York, NY, USA, 2016; pp. 513-521.

16. Parks, S.E.; Clark, C.W.; Tyack, P.L. Short-and long-term changes in right whale calling behavior: The potential effects of noise on acoustic communication. J. Acoust. Soc. Am. 2007, 122, 3725-3731. [CrossRef] [PubMed]

17. Picciulin, M.; Sebastianutto, L.; Codarin, A.; Farina, A.; Ferrero, E.A. In situ behavioural responses to boat noise exposure of Gobius cruentatus (Gmelin, 1789; fam. Gobiidae) and Chromis chromis (Linnaeus, 1758; fam. Pomacentridae) living in a Marine Protected Area. J. Exp. Mar. Biol. Ecol. 2010, 386, 125-132. [CrossRef]

18. Chao, L.N. Sciaenidae. Fishes North-East. Atl. Mediterr. 1986, 2, 865-874.

19. Nelson, J.S. Fishes of the World, 3rd ed.; John Wiley and Sons: Hoboken, NJ, USA, 1994.

20. Ramcharitar, J.; Gannon, D.P.; Popper, A.N. Bioacoustics of fishes of the family Sciaenidae (croakers and drums). Trans. Am. Fish. Soc. 2006, 135, 1409-1431. [CrossRef]

21. Connaughton, M.A.; Taylor, M.H. Seasonal and daily cycles in sound production associated with spawning in the weakfish, Cynoscion regalis. Environ. Biol. Fishes 1995, 42, 233-240. [CrossRef]

22. Mok, H.-K.; Gilmore, R.G. Analysis of sound production in estuarine aggregations of Pogonias cromis, Bairdiella chrysoura, and Cynoscion nebulosus (Sciaenidae). Bull. Inst. Zool. Acad. Sin. 1983, 22, 157-186.

23. Azpelicueta, M.L.M.; Delpiani, S.M.; Cione, A.L.; Oliveira, C.; Marceniuk, A.P.; de Astarloa Díaz, J.M. Morphology and molecular evidence support the validity of Pogonias courbina (Lacepède, 1803) (Teleostei: Sciaenidae), with a redescription and neotype designation. PLoS ONE 2019, 14, e0216280. [CrossRef]

24. Macchi, G.J.; Acha, E.M.; Lasta, C.A. Reproduction of black drum (Pogonias cromis) in the Rio de la Plata estuary, Argentina. Fish. Res. 2002, 59, 83-92. [CrossRef] 
25. Cousseau, M.B.; Perrotta, R.G. Peces Marinos de Argentina. Biologıa, Distribucion, Pesca; INIDEP: Mar del Plata, Argentina, 2004; ISBN 987-20245-4-5.

26. Norbis, W.; Paesch, L.; Galli, O. Los recursos pesqueros de la costa de Uruguay: Ambiente, biología y gestión. In Bases Para La Conservación y el Manejo de la Costa Uruguaya; Menafra, R., Rodriguez-Gallego, L., Scarabino, F., Eds.; Vida Silvestre Uruguay: Montevideo, Uruguay, 2006; pp. 197-209.

27. Locascio, J.V.; Burghart, S.; Mann, D.A. Quantitative and temporal relationships of egg production and sound production by black drum Pogonias cromis. J. Fish. Biol. 2012, 81, 1175-1191. [CrossRef] [PubMed]

28. Locascio, J.V.; Mann, D.A. Localization and source level estimates of black drum (Pogonias cromis) calls. J. Acoust. Soc. Am. 2011, 130, 1868-1879. [CrossRef] [PubMed]

29. Tellechea, J.S.; Norbis, W.; Olsson, D.; Fine, M.L. Calls of the black drum (Pogonias cromis: Sciaenidae): Geographical differences in sound production between northern and southern hemisphere populations. J. Exp. Zool. Part Ecol. Genet. Physiol. 2011, 315A, 48-55. [CrossRef]

30. Ramcharitar, J.; Popper, A.N. Masked auditory thresholds in sciaenid fishes: A comparative study. J. Acoust. Soc. Am. 2004, 116, 1687-1691. [CrossRef] [PubMed]

31. Locascio, J.V.; Mann, D.A. Diel and seasonal timing of sound production by black drum (Pogonias cromis). Fish. Bull. 2011, 109, 327-338.

32. Nieland, D.L.; Wilson, C.A. Reproductive biology and annual variation of reproductive variables of black drum in the northern Gulf of Mexico. Trans. Am. Fish. Soc. 1993, 122, 318-327. [CrossRef]

33. Blom, E.-L.; Kvarnemo, C.; Dekhla, I.; Schöld, S.; Andersson, M.H.; Svensson, O.; Amorim, M.C.P. Continuous but not intermittent noise has a negative impact on mating success in a marine fish with paternal care. Sci. Rep. 2019, 9, 5494. [CrossRef]

34. Hawkins, A.D.; Popper, A.N. A sound approach to assessing the impact of underwater noise on marine fishes and invertebrates. ICES J. Mar. Sci. 2017, 74, 635-651. [CrossRef]

35. Papale, E.; Gamba, M.; Perez-Gil, M.; Martin, V.M.; Giacoma, C. Dolphins Adjust Species-Specific Frequency Parameters to Compensate for Increasing Background Noise. PLoS ONE 2015, 10, e0121711. [CrossRef]

36. Spiga, I.; Aldred, N.; Caldwell, G.S. Anthropogenic noise compromises the anti-predator behaviour of the European seabass, Dicentrarchus labrax (L.). Mar. Pollut. Bull. 2017, 122, 297-305. [CrossRef] [PubMed]

37. Smott, S.; Monczak, A.; Miller, M.E.; Montie, E.W. Boat noise in an estuarine soundscape-A potential risk on the acoustic communication and reproduction of soniferous fish in the May River, South Carolina. Mar. Pollut. Bull. 2018, 133, 246-260. [CrossRef]

38. Vasconcelos, R.O.; Amorim, M.C.P.; Ladich, F. Effects of ship noise on the detectability of communication signals in the Lusitanian toadfish. J. Exp. Biol. 2007, 210, 2104-2112. [CrossRef] [PubMed]

39. de Jong, K.; Forland, T.N.; Amorim, M.C.P.; Rieucau, G.; Slabbekoorn, H.; Sivle, L.D. Predicting the effects of anthropogenic noise on fish reproduction. Rev. Fish. Biol. Fish. 2020, 30, 245-268. [CrossRef]

40. Picciulin, M.; Sebastianutto, L.; Codarin, A.; Calcagno, G.; Ferrero, E.A. Brown meagre vocalization rate increases during repetitive boat noise exposures: A possible case of vocal compensation. J. Acoust. Soc. Am. 2012, 132, 3118-3124. [CrossRef] [PubMed]

41. Holt, D.E.; Johnston, C.E. Evidence of the Lombard effect in fishes. Behav. Ecol. 2014, 25, 819-826. [CrossRef]

42. de Jong, K.; Amorim, M.C.P.; Fonseca, P.J.; Fox, C.J.; Heubel, K.U. Noise can affect acoustic communication and subsequent spawning success in fish. Environ. Pollut. 2018, 237, 814-823. [CrossRef]

43. Isla, F.I. Seasonal behaviour of Mar Chiquita tidal inlet in relation to adjacent beaches, Argentina. J. Coast. Res. 1997, 13, 1221-1232.

44. Iribarne, O. Reserva de Biosfera Mar Chiquita: Características Físicas, Biológicas y Ecológicas; Editorial Martín: Mar del Plata, Argentina, 2001.

45. Isacch, J.P. Implementing the biosphere reserve concept: The case of Parque Atlántico Mar Chiquito biosphere reserve from Argentina. Biodivers. Conserv. 2008, 17, 1799-1804. [CrossRef]

46. Cousseau, M.B.; Díaz de Astarloa, J.M.; Figueroa, D.E. La ictiofauna de la laguna Mar Chiquita. In Reserva de Biosfera Mar Chiquita Características Físicas Biológicas Ecológicas; Iribarne, O., Ed.; Editorial Martín: Mar del Plata, Argentina, 2001 ; pp. 187-203.

47. Lucifora, L.O. Tiburones y Pesca de Tiburones en Mar Chiquita; Editorial Martín: Mar del Plata, Argentina, 2001.

48. Bruno, D.O.; Barbini, S.A.; Díaz de Astarloa, J.M.; Martos, P. Fish abundance and distribution patterns related to environmental factors in a choked temperate coastal lagoon (Argentina). Braz. J. Oceanogr. 2013, 61, 43-53. [CrossRef]

49. González Castro, M.; Díaz de Astarloa, J.M.; Cousseau, M.B.; Figueroa, D.E.; Delpiani, S.M.; Bruno, D.O.; Guzzoni, J.M.; Blasina, G.E.; Deli Antoni, M.Y. Fish composition in a south-western Atlantic temperate coastal lagoon: Spatial-temporal variation and relationships with environmental variables. J. Mar. Biol. Assoc. UK 2009, 89, 593-604. [CrossRef]

50. Filiciotto, F.; Sal Moyano, M.P.; Hidalgo, F.; de Vincenzi, G.; Bazterrica, M.C.; Ceraulo, M.; Corrias, V.; Quinci, E.M.; Lorusso, M.; Mazzola, S.; et al. Underwater acoustic communication during the mating behaviour of the semi-terrestrial crab Neohelice Granulata. Sci. Nat. 2019, 106, 35. [CrossRef] [PubMed]

51. Sal Moyano, M.P.; Ceraulo, M.; Mazzola, S.; Buscaino, G.; Gavio, M.A. Sound production mechanism in the semiterrestrial crab Neohelice granulata (Brachyura, Varunidae). J. Acoust. Soc. Am. 2019, 146, 3466-3474. [CrossRef]

52. Ceraulo, M.; Sal Moyano, M.P.; Bazterrica, M.C.; Hidalgo, F.J.; Papale, E.; Grammauta, R.; Gavio, M.A.; Mazzola, S.; Buscaino, G. Spatial and temporal variability of the soundscape in a Southwestern Atlantic coastal lagoon. Hydrobiologia 2020, 847, 2255-2277. [CrossRef] 
53. Marcovecchio, J.; Freije, H.; De Marco, S.; Gavio, A.; Ferrer, L.; Andrade, S.; Beltrame, O.; Asteasuain, R. Seasonality of hydrographic variables in a coastal lagoon: Mar Chiquita, Argentina. Aquat. Conserv. Mar. Freshw. Ecosyst. 2006, 16, $335-347$. [CrossRef]

54. Bazterrica, M.C.; Bruschetti, C.M.; Alvarez, M.F.; Iribarne, O.; Botto, F. Effects of Macroalgae on the Recruitment, Growth, and Body Condition of an Invasive Reef Forming Polychaete in a South-Western Atlantic Coastal Lagoon. J. Sea Res. 2014, 88, 121-129. [CrossRef]

55. Reta, R.; Martos, P.; Perillo, G.M.E.; Piccolo, M.C.; Ferrante, A. Características hidrográficas del estuario de la laguna Mar Chiquita. In Reserva de Biosfera Mar Chiquita: Características Físicas Biológicas Ecológicas; Editorial Martín: Mar del Plata, Argentina, 2001; pp. 31-52.

56. Fasano, J.L.; Hernandez, M.; Isla, F.I.; Schnack, E.J. Aspectos evolutivos y ambientales de la laguna Mar Chiquita (provincia de Buenos Aires, Argentina). Oceanol. Acta 1982, 185-292. Available online: https://pascal-francis.inist.fr/vibad/index.php?action= getRecordDetail\&idt=12189619 (accessed on 22 December 2020).

57. Li, S.; Wu, H.; Xu, Y.; Peng, C.; Fang, L.; Lin, M.; Xing, L.; Zhang, P. Mid- to high-frequency noise from high-speed boats and its potential impacts on humpback dolphins. J. Acoust. Soc. Am. 2015, 138, 942-952. [CrossRef]

58. Hildebrand, J.A. Anthropogenic and natural sources of ambient noise in the ocean. Mar. Ecol. Prog. Ser. 2009, 395, 5-20. [CrossRef]

59. Bates, D.; Maechler, M.; Bolker, B. lme4: Linear Mixed-Effects Models Using S4 Classes 2012. R package version 0.999999-0. Available online: http:/ / cran.r-project.org/web/packages/lme4/index.html (accessed on 22 December 2020).

60. Forrest, T.; Miller, G.; Zagar, J. Sound propagation in shallow water: Implications for acoustic communication by aquatic animals. Bioacoustics 1993, 4, 259-270. [CrossRef]

61. Slabbekoorn, H.; Bouton, N.; van Opzeeland, I.; Coers, A.; ten Cate, C.; Popper, A.N. A noisy spring: The impact of globally rising underwater sound levels on fish. Trends Ecol. Evol. 2010, 25, 419-427. [CrossRef] [PubMed]

62. Clark, C.W.; Ellison, W.T.; Southall, B.L.; Hatch, L.; Van Parijs, S.M.; Frankel, A.; Ponirakis, D. Acoustic masking in marine ecosystems: Intuitions, analysis, and implication. Mar. Ecol. Prog. Ser. 2009, 395, 201-222. [CrossRef]

63. Voellmy, I.K.; Purser, J.; Flynn, D.; Kennedy, P.; Simpson, S.D.; Radford, A.N. Acoustic noise reduces foraging success in two sympatric fish species via different mechanisms. Anim. Behav. 2014, 89, 191-198. [CrossRef]

64. Ferrari, M.C.; McCormick, M.I.; Meekan, M.G.; Simpson, S.D.; Nedelec, S.L.; Chivers, D.P. School is out on noisy reefs: The effect of boat noise on predator learning and survival of juvenile coral reef fishes. Proc. R. Soc. B Biol. Sci. 2018, 285, 20180033. [CrossRef]

65. Codarin, A.; Wysocki, L.E.; Ladich, F.; Picciulin, M. Effects of ambient and boat noise on hearing and communication in three fish species living in a marine protected area (Miramare, Italy). Mar. Pollut. Bull. 2009, 58, 1880-1887. [CrossRef]

66. Ladich, F. Effects of noise on sound detection and acoustic communication in fishes. In Animal Communication and Noise; Springer: Berlin/Heidelberg, Germany, 2013; pp. 65-90.

67. Bruintjes, R.; Radford, A.N. Chronic playback of boat noise does not impact hatching success or post-hatching larval growth and survival in a cichlid fish. PeerJ 2014, 2, e594. [CrossRef]

68. Nedelec, S.L.; Mills, S.C.; Lecchini, D.; Nedelec, B.; Simpson, S.D.; Radford, A.N. Repeated exposure to noise increases tolerance in a coral reef fish. Environ. Pollut. 2016, 216, 428-436. [CrossRef]

69. Mauro, M.; Pérez-Arjona, I.; Perez, E.J.B.; Ceraulo, M.; Bou-Cabo, M.; Benson, T.; Espinosa, V.; Beltrame, F.; Mazzola, S.; Vazzana, M. The effect of low frequency noise on the behaviour of juvenile Sparus Aurata. J. Acoust. Soc. Am. 2020, 147, 3795-3807. [CrossRef] 